\title{
Numerous IgG4-positive plasma cells are ubiquitous in diverse localised non-specific chronic inflammatory conditions and need to be distinguished from IgG4-related systemic disorders
}

\author{
Johanna D Strehl, Arndt Hartmann, Abbas Agaimy
}

Institute of Pathology, University of Erlangen, Erlangen, Germany

\section{Correspondence to}

Professor Abbas Agaimy,

Pathologisches Institut,

Krankenhausstrasse 12, 91054

Erlangen, Germany;

abbas.agaimy@uk-erlangen.de

Accepted 9 December 2010 Published Online First

12 January 2011

\section{ABSTRACT}

Background IgG4-related systemic fibrosclerosis is a recently defined disorder characterised by a diffuse or tumefactive inflammatory reaction rich in IgG4-positive plasma cells associated with sclerosis and obliterative phlebitis. Although characteristic histopathological features are essential for the diagnosis of these disorders, to date there exists no consensus regarding the cut-off values used to define a 'significant IgG4positive plasma cell count,' and data regarding the distribution of IgG4-positive plasma cells under common (non-specific) inflammatory conditions are lacking.

Methods The authors analysed 121 randomly selected histopathological specimens containing prominent lymphoplasmacytic infiltrates (11 obstructive sialadenitis, 27 inflammatory lesions of the oral cavity, 24 inflammatory gastrointestinal lesions, 15 rheumatoid synovitis, 15 non-specific synovitis, eight non-specific dermatitis and 21 primary carcinomas with a peritumoral inflammatory response). For comparison, seven cases of sclerosing sialadenitis (Küttner tumour) were examined. Results High counts of IgG4 plasma cells were found in sclerosing sialadenitis (mean 40/high-power field (hpf)), contrasting sharply with sialadenitis caused by sialolithiasis (mean $3 / \mathrm{hpf}$ ). Greatly varied but generally high counts of IgG4-positive plasma cells were also seen in several of the other lesions, particularly in rheumatoid synovitis (mean 55/hpf), oral cavity lesions (mean 79/ hpf) and carcinoma-associated inflammatory response (mean 24/hpf). The mean IgG4/lgG ratios for all lesions varied between 0 and 0.4 .

Conclusions The results demonstrate the ubiquitous occurrence of variably high numbers of IgG4-positive plasma cells under diverse non-specific inflammatory conditions, indicating that high lgG4-positive plasma cell counts and high IgG4/lgG ratios per se do not reliably distinguish IgG4-associated systemic disease from nonspecific conditions, and that the IgG4 counts must be cautiously interpreted in the context of appropriate clinical and histopathological features.

\section{INTRODUCTION}

IgG4-associated sclerosing disease (ISD) has emerged recently as a unifying concept for several previously described inflammatory organ-specific conditions characterised by an elevated serum level of IgG4 and the occurrence of sclerosing lymphoplasmacytic inflammatory reaction rich in IgG4positive plasma cells in one or more organs. ${ }^{1-4}$ Autoimmune pancreatitis (AIP) represents the prototype of these disorders and has been the subject of extensive studies. ${ }^{5-8}$ Recent publications have documented similar lesions in almost all body organ systems, including in particular sclerosing cholangitis, ${ }^{9}$ sclerosing sialadenitis/Küttner tumour, ${ }^{10}{ }^{11}$ chronic sclerosing dacryocystitis, ${ }^{12}$ idiopathic retroperitoneal fibrosis, ${ }^{13}$ sclerosing angiomatoid nodular transformation of the spleen ${ }^{14}$ as well as IgG4-related renal, ${ }^{15}$ lymphadenopathic, ${ }^{16}$ hypophyseal, ${ }^{17}$ mediastinal, ${ }^{18}$ pleuropulmonary ${ }^{19}$ and soft-tissue ${ }^{20}$ diseases. The diagnosis of any of these conditions is based on a set of both clinical and histopathological features. Dense lymphoplasmacytic infiltrates rich in IgG4-positive plasma cells accompanied by a prominent (typically storiform) sclerosis and obliterative phlebitis are considered the histopathological hallmarks of ISD.

As these fibroinflammatory conditions frequently present as tumefactive lesions, concern about malignancy may prompt biopsy of the lesion. Thus, pathologists are increasingly being confronted with this differential diagnostic challenge. Several working groups have attempted to define a set of diagnostic criteria based on clinical and histopathological characteristics which allows a precise and reliable diagnosis of AIP and other ISD. However, the reliability of histopathological evaluation in the diagnosis of ISD has been challenged by the fact that variable recommendations exist by different working groups, in particular regarding the most appropriate threshold to define a 'significant IgG4positive plasma cell count.' Thus, variable cut-off values of $>10,{ }^{5} 2122>20^{23} 24$ and $>50^{25}$ IgG4positive plasma cells/high-power field (hpf) have been used to define AIP in different publications. Other groups have suggested a four-tiered scoring system to assess the severity of IgG4-positive plasma cell infiltrates as severe ( $>30 / \mathrm{hpf})$, moderate (10-30/hpf), slight (5-10/hpf) and few ( $<5 / \mathrm{hpf}){ }^{26} 27$ However, this scoring system does not take into account the density of plasma cell aggregates and thus does not help to distinguish between 'real' ISD and lesions that fall into the 'physiological' range of IgG4-positive plasma cell infiltration in ordinary non-specific inflammatory conditions. The use of IgG4/IgG ratios proved to be more valuable in identifying ISD than the absolute counts of IgG4 plasma cells. In their cross-sectional study of 115 cases of ISD in the most recent study, Zen et al used an IgG4/IgG ratio of 0.3 as a threshold for the diagnosis of ISD. ${ }^{28}$ To our knowledge, the distribution and ranges of IgG4-positive plasma cells as 
a possible component in ordinary (non-specific) chronic inflammatory conditions from different organ systems have not been sufficiently studied yet. This was the aim of this study.

\section{MATERIAL AND METHODS \\ Case material and selection criteria}

We analysed 121 specimens from 121 patients (100 chronic plasma cell-rich inflammatory conditions and 21 carcinoma specimens with a prominent peri-/intratumoral inflammatory response) retrieved from the routine surgical pathology files at our institution. The inflammatory conditions included 11 cases of obstructive sialadenitis caused by sialolithiasis, 27 inflammatory lesions of the oral cavity (12 cases of plasma cell epulis, 11 cases of radicular cyst/apical granuloma, four cases of lichen ruber), 24 lesions of the lower gastrointestinal tract (nine cases of Crohn disease, nine cases of ulcerative colitis, six cases of sigmoid diverticulitis), 15 cases of clinically proven rheumatoid synovitis, 15 cases of non-specific synovitis (five cases of Perthes disease, 10 cases of degenerative joint disease), and eight cases of plasma cell-rich dermatitis (four cases of lichen sclerosus et atrophicans, two cases of anus praeter associated inflammatory reaction and one case each of posthitis and unguis incarnatus). In addition, 11 squamous cell carcinomas (four vulva and seven oral cavity) and 10 adenocarcinomas (four pancreas, two colon, two lung, two breast) with an antitumoral inflammatory response rich in plasma cells were included. Based on the available clinical records, none of the patients included had clinical signs of AIP or other condition related to ISD. Age was not a criterion in case selection, and a wide age range has been included as determined by specimen type. For comparison purposes, seven cases of IgG4 associated sclerosing sialadenitis (Küttner tumour) were stained. This study is covered by ethical votum of the medical faculty of the University of ErlangenNuremberg.

\section{Immunohistochemistry}

Tissue samples were routinely fixed in buffered formalin and embedded in paraffin. Immunohistochemistry was carried out on $4 \mu \mathrm{m}$ sections using a polymer Kit purchased from Zytomed systems (Berlin, Germany) according to the manufacturer's instructions and the following antibodies: rabbit polyclonal antibody against human IgG (1:2000, DAKO, Denmark, pretreament with Pronase), mouse monoclonal antibody against human IgG4 (clone MCA2098G, 1:100, SeroTec, UK, pretreatment with citrate buffer) and mouse monoclonal antibody against human CD138 (clone Mi15, 1:500, DAKO, Denmark, pretreatment with citrate buffer).

H\&E-stained sections and sections stained with CD138 were evaluated, and the area with the highest density of plasma cell infiltration was identified and marked. IgG-positive and IgG4positive plasma cells were counted in five high-power fields (one hpf corresponded to an area of $0.238 \mathrm{~mm}^{2}$ ) within the previously marked areas with the highest plasma cell infiltration. The mean number of positive cells per hpf and the ratios of IgG4:IgGpositive plasma cells were calculated. Examination of tissue samples treated with IgG4 antibody revealed subsets of IgG4positive and IgG4-negative plasma cells, thus demonstrating the specificity of the staining. Only cells with clear-cut strong cytoplasmic reactivity were considered positive.

\section{Statistical analysis}

The Student t test was used to assess the statistical significance between different groups. A $p$ value of $<0.05$ was considered significant, and a $\mathrm{p}$ value of $<0.01$ was considered highly significant.

\section{RESULTS (summarised in Table 1) Chronic obstructive sialadenitis and sclerosing sialadenitis/ Küttner tumour}

Seven cases of autoimmune sclerosing sialadenitis (Küttner tumour) were examined for comparison purposes. The seven cases showed an average of 40 IgG4-positive plasma cells/hpf (range $4-104 / \mathrm{hpf}$ ). The IgG4/IgG ratio varied from 0.23 to 0.73 (mean 0.59 ) (figure $1 \mathrm{~A}-\mathrm{C}$ ). In contrast, the 11 cases of nonspecific obstructive sialadenitis associated with sialolithiasis showed low counts of IgG4-positive plasma cells/hpf, the values ranging from 0 to $27 / \mathrm{hpf}$ (mean $3 / \mathrm{hpf}$ ) with a mean $\operatorname{IgG} 4 / \mathrm{IgG}$ ratio of 0.02 (range $0-0.15$ ). Statistical analysis demonstrated a significant difference between absolute IgG4 plasma cell counts $(p=0.023)$ and $\operatorname{IgG} 4 / \operatorname{IgG}$ ratios $(p=0.0018)$ regarding the groups of Küttner tumour and sialolithiasis-associated sialadenitis.

Table 1 Distribution of the $\lg G 4$ counts and the $\operatorname{lgG} 4 / \lg G$ ratios in the study cohort ( $n=128$ including the seven Küttner tumour cases)

\begin{tabular}{|c|c|c|c|c|c|c|c|}
\hline Localisation & Diagnosis & $\mathbf{n}$ & $\begin{array}{l}\text { Mean IgG4/ } \\
\text { hpf }\end{array}$ & $\begin{array}{l}\text { Range IgG4/ } \\
\text { hpf }\end{array}$ & $\begin{array}{l}\text { Mean IgG/ } \\
\text { hpf }\end{array}$ & $\begin{array}{l}\text { IgG4/IgG } \\
\text { mean ratio }\end{array}$ & $\begin{array}{l}\text { Range } \lg \mathrm{G4} / \\
\text { IgG ratio }\end{array}$ \\
\hline \multirow[t]{2}{*}{ Salivary glands } & Sclerosing sialadenitis/Küttner tumour & 7 & 40 & $4-104$ & 74 & 0.59 & $0.23-1$ \\
\hline & Sialadenitis caused by sialolithiasis & 11 & 3 & $0-26.8$ & 54.0 & 0.02 & $0-0.15$ \\
\hline \multirow[t]{4}{*}{ Oral cavity } & All lesions & 27 & 79 & $0-235$ & 235 & 0.32 & $0-0.84$ \\
\hline & Epulis plasmocellularis & 12 & 69 & $27-102$ & 232 & 0.32 & $0.18-0.77$ \\
\hline & Radicular cysts & 11 & 93 & $23.3-234$ & 278 & 0.32 & $0.1-0.84$ \\
\hline & Oral lichen ruber & 4 & 67 & $0-217$ & 126 & 0.35 & $0-0.84$ \\
\hline \multirow{4}{*}{$\begin{array}{l}\text { Lower gastrointestinal } \\
\text { tract }\end{array}$} & All lesions & 24 & 11 & $0-40$ & 187 & 0.06 & $0-0.2$ \\
\hline & Crohn's disease & 9 & 8 & $1-22$ & 160 & 0.046 & $0.008-0.08$ \\
\hline & Ulcerative colitis & 9 & 8 & $0-18$ & 210 & 0.04 & $0-0.06$ \\
\hline & Diverticulitis & 6 & 19 & $0-40$ & 194 & 0.11 & $0-0.2$ \\
\hline \multirow[t]{3}{*}{ Synovitis } & All lesions & 30 & 35 & $0-181$ & 122 & 0.27 & $0-1$ \\
\hline & Rheumatoid arthritis & 15 & 55 & $0-181$ & 153 & 0.4 & $0-1$ \\
\hline & Non-specific synovitis & 15 & 15 & $0-79$ & 92 & 0.15 & $0-0.44$ \\
\hline \multirow[t]{3}{*}{ Carcinomas } & All lesions & 21 & 24 & $0-88$ & 117 & 0.22 & $0-0.51$ \\
\hline & Adenocarcinomas & 10 & 6 & $0-88$ & 73 & 0.21 & $0-0.48$ \\
\hline & Squamous cell carcinomas & 11 & 34 & $1-81$ & 156 & 0.23 & $0-0.51$ \\
\hline Skin & All lesions & 8 & 26 & $1-120$ & 85 & 0.21 & $0.04-0.67$ \\
\hline
\end{tabular}

hpf, high-power field. 

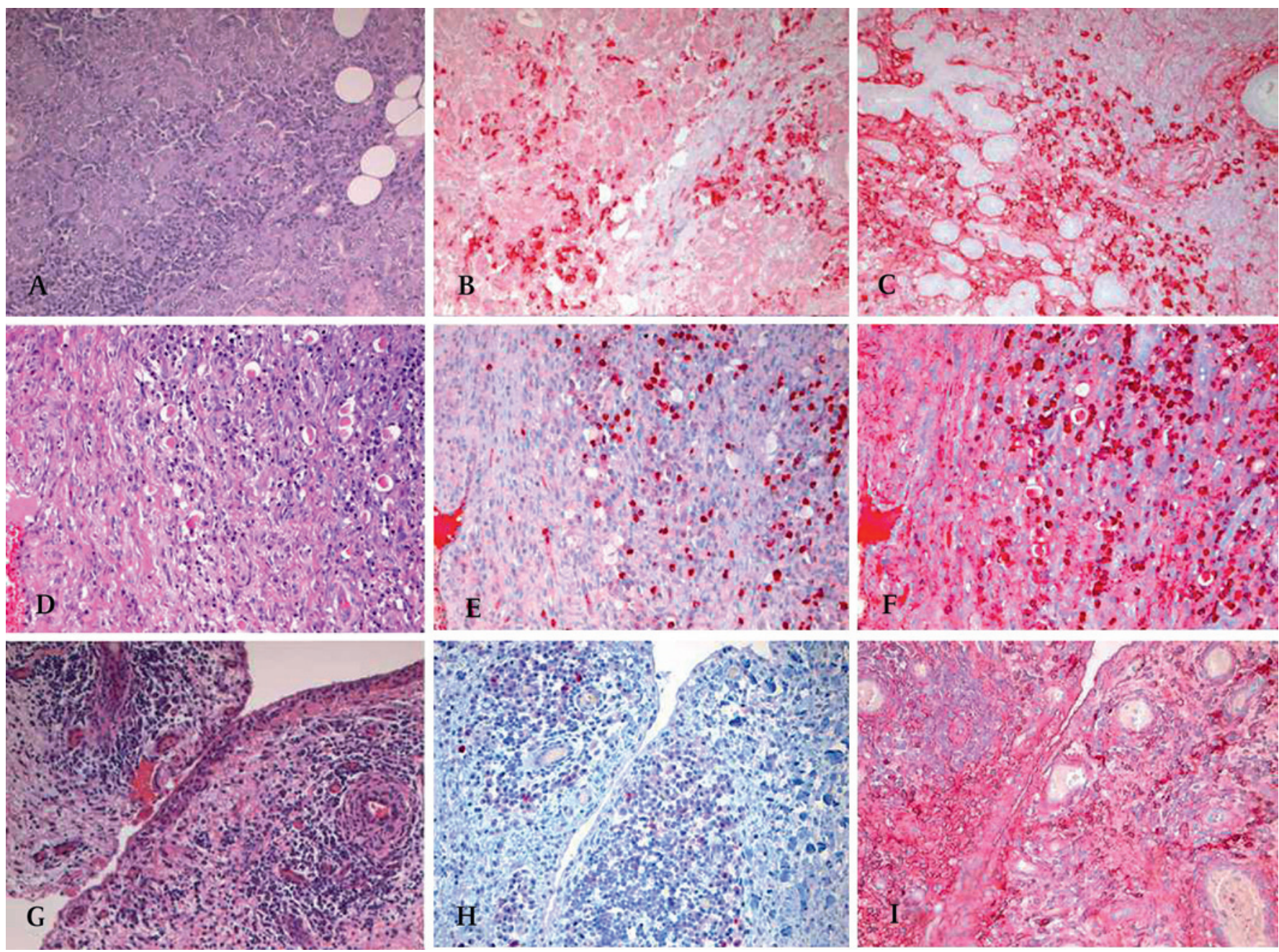

Figure 1 Representative images of H\&E (left column), IgG4 (mid-column) and IgG (right column) from chronic inflammatory conditions (original magnification: $200 \times$ ). (A-C) Sclerosing sialadenitis, Küttner tumour. (D-F) Rheumatoid synovitis. (G-I) Non-specific synovitis.

\section{IgG4-positive plasma cells in rheumatoid synovitis and non-specific synovitis}

In the 15 cases of clinically proven rheumatoid synovitis (figure $1 \mathrm{D}-\mathrm{F}$ ), the counts of IgG4-positive plasma cells ranged from 0 to 181/hpf (mean 55/hpf), and the IgG4/IgG ratio varied between 0 and 1.0 (mean 0.4). In contrast to this, the 15 cases of synovitis without a clinical diagnosis of rheumatoid arthritis showed a significantly lower level of IgG4-positive plasma cells (mean 15/ hpf; range 0-79) (figure $1 \mathrm{G}-\mathrm{I}$ ). The $\mathrm{IgG} 4 / \mathrm{IgG}$ ratio in the nonspecific synovitis cases ranged between 0 and 0.44 (mean 0.15 ). Interestingly, three cases from the non-specific synovitis group displayed high IgG4-positive plasma cell counts (between 40 and 79 IgG4-positive plasma cells/hpf; IgG4/IgG ratio between 0.4 and 0.72 ). In one of these cases, the histological findings were suggestive of rheumatoid arthritis, but clinical data were inconclusive, and an infectious aetiology could not be definitely ruled out. Statistical analysis showed a significant difference between both the absolute IgG4 plasma cell counts $(p=0.014)$ and the $\operatorname{IgG} 4 / \operatorname{IgG}$ ratios $(p=0.027)$ regarding the groups of rheumatoid synovitis and non-specific (non-rheumatoid) synovitis.

\section{IgG4-positive plasma cells in chronic inflammatory lesions of the oral cavity}

Taken together, the 27 inflammatory oral lesions showed a mean of 79 IgG4-positive plasma cells/hpf (range 0-235/hpf). The IgG4/IgG ratios ranged from 0 to 0.84 (mean 0.32). The mean
IgG4-positive plasma cell counts were 69 and 93/hpf for the plasma cell epulis and radicular cysts/apical granuloma cases respectively. The four cases of lichen ruber mucosae showed a mean of 67 IgG4-positive plasma cells/hpf. The respective mean $\operatorname{IgG} 4 / \mathrm{IgG}$ ratios were 0.32 for plasma cell epulis and radicular cyst/apical granuloma and 0.35 for lichen ruber mucosae. The numerous IgG4-positive plasma cells were generally evenly distributed throughout the lesion in all the oral cavity lesions with occasional small dense aggregates (figure $2 \mathrm{~A}-\mathrm{C}$ ).

\section{IgG4 in chronic inflammatory conditions of the lower gastrointestinal tract}

The nine cases of Crohn disease showed a mean of 8 IgG4positive plasma cells/hpf (range $1-22 / \mathrm{hpf}$ ). The IgG4/IgG ratio varied between 0 and 0.08 (mean 0.05). The nine cases of ulcerative colitis showed similar counts of IgG4-positive plasma cells $(1-18 / \mathrm{hpf}$; mean $8 / \mathrm{hpf})$ with an IgG4/IgG ratio between 0 and 0.06 (mean 0.04). Furthermore, six cases of sigmoid colon diverticulitis were assessed. Here, the IgG4-positive plasma cell count varied between 0 and 40/hpf (mean 19/hpf), with an $\operatorname{IgG} 4 / \mathrm{IgG}$ ratio between 0 and 0.2 (mean 0.11 ). Taken together, gastrointestinal tract lesions showed a mean of 11 IgG4-positive plasma cells per hpf (range $0-40 / \mathrm{hpf}$ ), and the IgG4/IgG ratio ranged between 0 and 0.2 (mean 0.06). Statistical analysis showed a highly significant difference regarding the absolute IgG4 plasma cell numbers $(p=<0.001)$ and the IgG4/IgG ratio 

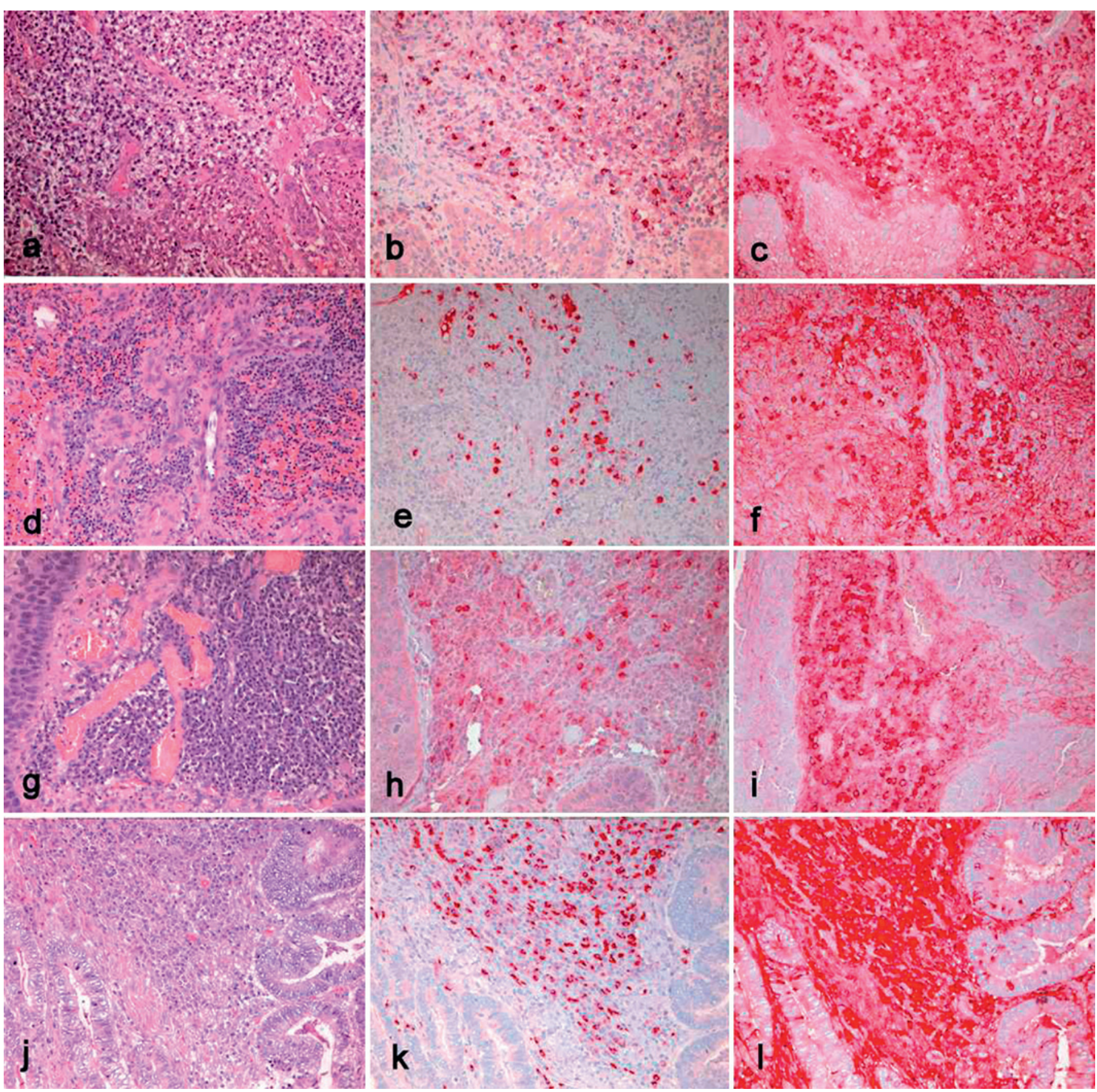

Figure 2 Representative images of H\&E (left column), IgG4 (mid-column) and lgG (right column) from chronic inflammatory conditions (original magnification: $200 \times$ ). (A-C) Plasma cell epulis. (D-F) Unguis incarnatus. (G-I) Squamous cell carcinoma. (J-L) Adenocarcinoma.

$(\mathrm{p}=<0.001)$ when comparing the lesions of the lower gastrointestinal tract with the oral cavity lesions.

\section{IgG4 in non-specific dermal inflammatory infiltrates}

This small subgroup of eight benign chronic inflammatory conditions of the skin showed between 1 and 120 IgG4-positive plasma cells/hpf (mean 26/hpf). The IgG4/IgG ratio varied between 0.04 and 0.67 (mean 0.42 ) (figure $2 \mathrm{D}-\mathrm{F}$ ). The four cases of lichen sclerosus et atrophicans showed only sparse infiltrates of IgG4-positive plasma cells (0-5/hpf, mean 2) with a ratio between 0.04 and 0.06 (mean 0.05 ). The highest density of IgG4positive plasma cells was found in the case of unguis incarnatus (120/hpf; IgG4/IgG ratio 0.67).

\section{IgG4-positive plasma in tumour-associated inflammatory \\ response}

For the group of carcinomas as a whole $(n=21,10 \times$ adenocarcinoma, $11 \times$ squamous cell carcinoma), the IgG4-positive plasma cell counts ranged between 0 and 88 (mean 24) and the IgG4/IgG ratios ranged between 0 and 0.51 (mean 0.22 ). Taken by histological subtype, IgG4-positive plasma cell counts averaged 34 cells/hpf and 6 cells/hpf for squamous cell carcinomas (figure 2G-I) and adenocarcinomas (figure 2J-L), respectively. In squamous cell carcinomas, 1-81 IgG4-positive plasma cells/ hpf were detected. The samples from adenocarcinomas contained between 0 and 88 IgG4-positive plasma cells/hpf. The average $\operatorname{IgG} / \operatorname{IgG}$ ratio was similar in squamous cell 
Figure 3 Box plot of absolute IgG4 plasma cell counts per hpf. The maximum outlier in each group is represented by a star. Horizontal lines represent thresholds for the diagnosis of lgG4-associated sclerosing disease (in particular autoimmune pancreatitis) defined in previous publications (reference number in parentheses).

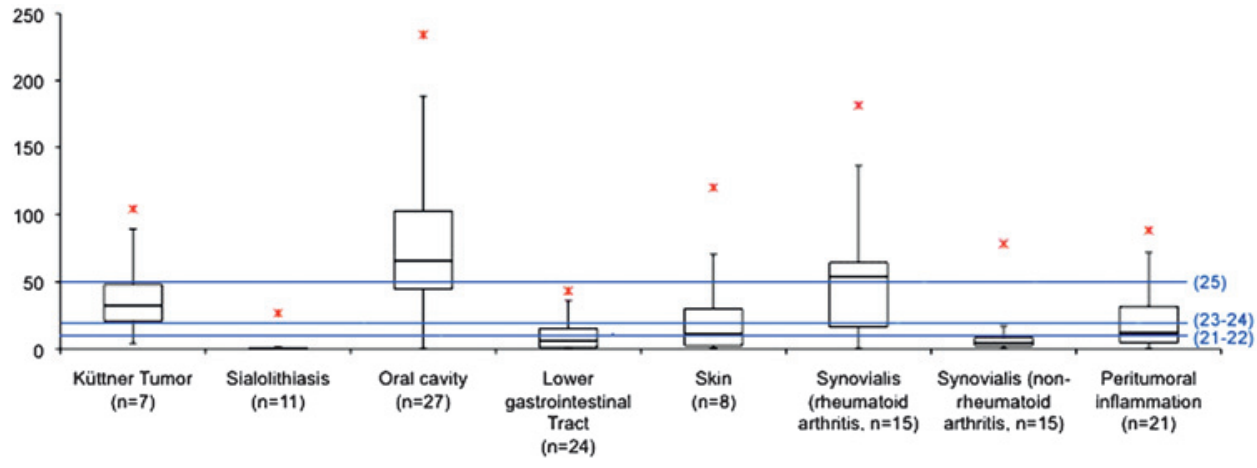

related to sialolithiasis was significantly lower than that reported for the autoimmune (IgG4-related) sclerosing sialadenitis/Küttner tumour in the current and previous studies ${ }^{10} 11$ with IgG4/IgG ratios of 0.02 versus 0.59 in our study. Similarly, the absolute IgG4 counts were significantly different in the two aetiological groups (3 vs 40/hpf). These findings underscore the value of the IgG4/IgG ratio and IgG4 count in this differential diagnosis in the salivary glands.

Cases of rheumatoid synovitis contained generally high but variable numbers of IgG4 plasma cells in this study. The degree to which the variation among individual patients with rheumatoid disease is due to anti-inflammatory treatment or possibly to differences in the levels of disease activity remains unclear. In the cases of synovitis without a clinical diagnosis of rheumatoid arthritis, the IgG4 counts per hpf and IgG4/IgG ratios were significantly lower $(p=0.026)$. These results suggest that an increased number of IgG4-positive plasma cells may be a finding specific to rheumatoid synovitis. Of the 15 cases of non-specific synovitis, three cases showed infiltrates of IgG4positive plasma cells in excess of 30 IgG4-positive plasma cells/ hpf. Careful re-evaluation of these samples showed a histomorphological picture compatible with rheumatoid disease in one case. However, clinical data regarding rheumatoid arthritis were inconclusive, and an infectious aetiology could not be definitely excluded in these cases. Unfortunately, we were not able to correlate our findings with serum IgG4, as this parameter is not measured routinely in most patients. Lin et al showed IgG4 serum levels to be elevated in patients with rheumatoid arthritis. ${ }^{29}$ Furthermore, Engelmann et al demonstrated that IgG4 significantly outweighs IgG2 and IgG3 among anticyclic citrullinated peptides (anti-CCP) antibodies in rheumatoid arthritis. ${ }^{30}$ Our current data indicate that IgG4-positive plasma cells are numerous in the synovial tissues of patients with rheumatoid arthritis and may thus be involved in the pathogenesis of this disease. However, further research based on larger
Figure 4 Box plot of $\lg \mathrm{G} 4 / \lg \mathrm{G}$ ratios The maximum outlier in each group is represented by a star. Horizontal lines represent thresholds for the diagnosis of ISD defined in previous publications (reference number in parentheses).

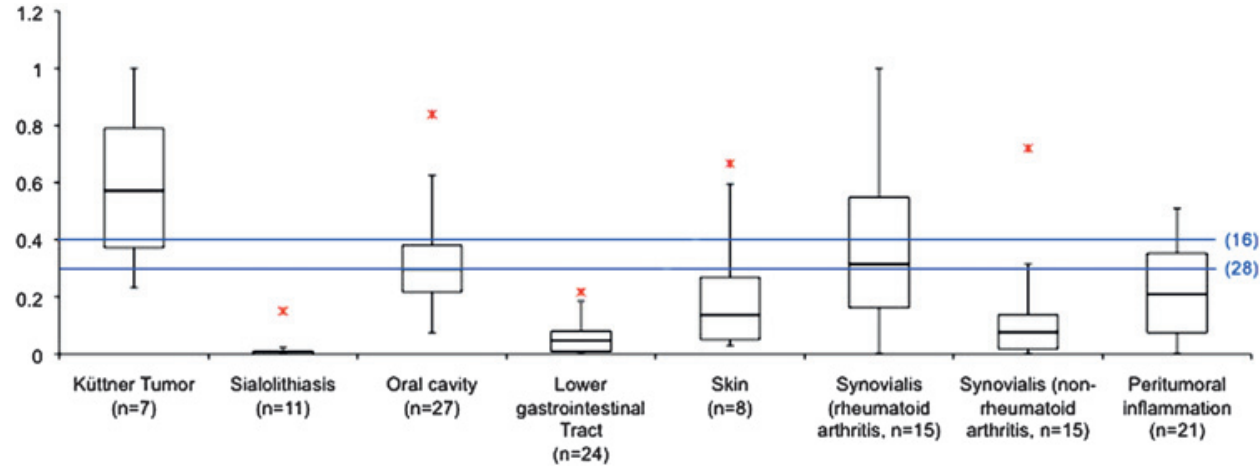


case series with a careful correlation of histopathological, clinical and serological data is needed to further substantiate this hypothesis.

Localised oral inflammatory lesions represent another subgroup with significant numbers of IgG4-positive plasma cells in this study. Using elispot immunoassays, Ogawa et al demonstrated that IgG4 expressing plasma cells are present in inflamed gingival tissue and documented a rise in IgG4 expression when comparing moderate parodontitis with advanced parodontitis. ${ }^{31}$ However, no detailed histopathological data are currently available regarding IgG4-positive plasma cells in gingival tissues. Our results suggest that lesions of the oral cavity may represent a variant of IgG4-rich localised inflammatory pseudotumour (inflammatory tumefactive lesion) unrelated to ISD. Interestingly, a recent study has described similar IgG4 plasma cell-rich localised tumefactive fibrous lesions in the gastrointestinal tract ${ }^{20}$ and the larynx, ${ }^{32}$ most of which were not associated with autoimmune systemic disease.

In this study, we found low numbers of IgG4 expressing plasma cells in the inflammatory infiltrates of Crohn disease and ulcerative colitis compared with sigmoid diverticulitis. Ravi et al hypothesised that the presence of IgG4-positive plasma cells in chronic inflammatory bowel disease may indicate an association with ISD and may thus represent a further extrapancreatic manifestation of AIP. ${ }^{33}$ However, the authors considered a number of 10 IgG4-positive plasma cells/hpf an 'increased infiltrate.' Our results showed both very low counts and counts in excess of 10 plasma cells in Crohn disease and ulcerative colitis, suggesting an even wider range of IgG4-positive plasma cells, most probably as a usual inflammatory cell component and not necessarily as an indication for a central role of IgG4 plasma cells in the pathogenesis of chronic inflammatory bowel disease. However, more extended future studies are needed to elucidate this matter further.

The analysis of eight cases of chronic inflammation in the skin yielded interesting results. We counted high numbers of IgG4positive plasma cells in unguis incarnatus (120/hpf) as well as in non-specific posthitis. In contrast, lichen sclerosus cases showed uniformly low numbers of IgG4-positive plasma cells (mean 2/ hpf). It is well known that serum IgG4 levels are elevated in patients with allergic symptoms and atopic dermatitis. ${ }^{34}$ Also, in pemphigus the autoantibodies belong mainly to the IgG4 and IgG1 subclasses. ${ }^{35}$ Our results show a great variation in the density of IgG4 plasma cells in our small group of non-specific chronic inflammatory skin lesions, thus underscoring the

\section{Take-home messages}

- IgG4-positive plasma cells constitute a common component of the inflammatory infiltrates in non-specific, non-ISD related chronic inflammatory lesions of different localisations.

- The intensity of IgG4-positive plasma cells in non-specific inflammation varies greatly depending on the lesion type and site.

- The ubiquity and the wide range of IgG4-positive plasma cells in non-specific chronic inflammation largely limit the establishment of a universally valid threshold of IgG4-positive plasma cell count for diagnosis of ISD.

- IgG4 plasma cells may play a role in the pathogenesis of rheumatoid synovitis and oral inflammatory lesions. necessity of careful interpretation of skin biopsy when looking for histological evidence of ISD.

In addition, we demonstrated that IgG4 plasma cells also represent a variable component of peritumoral/intratumoral inflammatory response to carcinomas of various types and locations. Again our results underscore the need to proceed with caution when the IgG4-positive plasma cell infiltration is used to differentiate between neoplasia and mass forming ISD. Our results showed up to 11 IgG4-positive plasma cells/hpf in pancreas specimens harbouring ductal adenocarcinoma. This is in accordance with a recent study by Dhall et al who showed that in peritumoral pancreatitis, up to 50 IgG4-positive plasma cells may be present per hpf. ${ }^{25}$ The presence of IgG4-positive plasma cells should therefore be considered suggestive of, but not necessarily diagnostic of, AIP. Other diagnostic criteria (imaging findings, serum IgG4 levels, typical histology) should always be taken into consideration in this context.

Our results clearly show that the number of IgG4-positive plasma cell infiltrates in plasma cell-rich inflammations from different locations and aetiologies may easily exceed the thresholds defined in the literature for ISD (figures 3, 4). The numbers of IgG4-positive plasma cells in diverse common inflammatory conditions vary greatly depending on localisation and aetiology. Our results demonstrate how difficult it would be to try to establish a universally valid threshold for 'significant IgG4 plasma cell count' for diagnosis of ISD disorders. Also, it is evident from our results that a threshold would not be suitable for all organ systems and that more extended studies are needed to try to define an organ-specific cut-off value for diagnosis of the different subsets of ISD. The presence of a tumefactive inflammatory infiltrate with prominent accompanying sclerosis and obliterative phlebitis are of particular importance when rendering a diagnosis of ISD. The plasma cell counts should be interpreted cautiously in the context of these typical histopathological features, thereby taking the serum IgG4 levels and other clinical findings (particularly the presence of similar manifestation in other organ systems) into consideration.

\section{Competing interests None.}

Provenance and peer review Not commissioned; externally peer reviewed.

\section{REFERENCES}

1. Bateman AC, Deheragoda MG. IgG4-related systemic sclerosing disease-an emerging and under-diagnosed condition. Histopathology 2009;55:373-83.

2. Cheuk W, Lee KC, Chong LY, et al. IgG4-related Sclerosing disease: a potential new etiology of cutaneous pseudolymphoma. Am J Surg Pathol 2009;33:1713-19.

3. Kamisawa T, Okamoto A. IgG4-related sclerosing disease. World J Gastroenterol 2008;14:3948-55.

4. Masaki Y, Dong L, Kurose N, et al. Proposal for a new clinical entity, IgG4-positive multiorgan lymphoproliferative syndrome: analysis of 64 cases of IgG4-related disorders. Ann Rheum Dis 2009;68:1310-15.

5. Chari ST, Smyrk TC, Levy MJ, et al. Diagnosis of autoimmune pancreatitis: the Mayo Clinic experience. Clin Gastroenterol Hepatol 2006;4:1010-16; quiz 934.

6. Kamisawa T, Okamoto A. Autoimmune pancreatitis: proposal of IgG4-related sclerosing disease. J Gastroenterol 2006;41:613-25.

7. Yoshida K, Toki F, Takeuchi T, et al. Chronic pancreatitis caused by an autoimmune abnormality. Proposal of the concept of autoimmune pancreatitis. Dig Dis Sci 1995; $40: 1561-8$

8. Zhang L, Smyrk TC. Autoimmune pancreatitis and IgG4-related systemic diseases Int J Clin Exp Pathol 2010;3:491-504.

9. Alderlieste YA, van den Elzen BD, Rauws EA, et al. Immunoglobulin G4-associated cholangitis: one variant of immunoglobulin G4-related systemic disease. Digestion 2009;79:220-8.

10. Geyer JT, Ferry JA, Harris NL, et al. Chronic sclerosing sialadenitis (Kuttner tumor) is an IgG4-associated disease. Am J Surg Pathol 2010;34:202-10.

11. Kitagawa S, Zen $Y$, Harada K, et al. Abundant IgG4-positive plasma cell infiltration characterizes chronic sclerosing sialadenitis (Kuttner's tumor). Am J Surg Pathol 2005;29:783-91.

12. Takahira M, Kawano M, Zen $\mathrm{Y}$, et al. IgG4-related chronic sclerosing dacryoadenitis Arch Ophthalmol 2007;125:1575-8. 
13. Zen Y, Onodera M, Inoue D, et al. Retroperitoneal fibrosis: a clinicopathologic study with respect to immunoglobulin G4. Am J Surg Pathol 2009;33:1833-9.

14. Diebold J, Le Tourneau A, Marmey B, et al. Is sclerosing angiomatoid nodular transformation (SANT) of the splenic red pulp identical to inflammatory pseudotumour? Report of 16 cases. Histopathology 2008:53:299-310.

15. Cornell LD, Chicano SL, Deshpande V, et al. Pseudotumors due to lgG4 immunecomplex tubulointerstitial nephritis associated with autoimmune pancreatocentric disease. Am J Surg Pathol 2007:31:1586-97.

16. Cheuk W, Yuen HK, Chu SY, et al. Lymphadenopathy of IgG4-related sclerosing disease. Am J Surg Pathol 2008;32:671-81.

17. Shimatsu A, Oki Y, Fujisawa I, et al. Pituitary and stalk lesions (infundibulohypophysitis) associated with immunoglobulin G4-related systemic disease: an emerging clinical entity. Endocr J 2009;56:1033-41.

18. Inoue M, Nose N, Nishikawa $\mathrm{H}$, et al. Successful treatment of sclerosing mediastinitis with a high serum IgG4 level. Gen Thorac Cardiovasc Surg 2007:55:431-3.

19. Zen Y, Inoue D, Kitao A, et al. IgG4-related lung and pleural disease: a clinicopathologic study of 21 cases. Am J Surg Pathol 2009;33:1886-93.

20. Chetty R, Serra S, Gauchotte G, et al. Sclerosing nodular lesions of the gastrointestinal tract containing large numbers of IgG4 plasma cells. Pathology 2011:43:31-5

21. Deheragoda MG, Church NI, Rodriguez-Justo M, et al. The use of immunoglobulin g4 immunostaining in diagnosing pancreatic and extrapancreatic involvement in autoimmune pancreatitis. Clin Gastroenterol Hepatol 2007;5:1229-34.

22. Detlefsen S, Mohr Drewes A, Vyberg $\mathrm{M}$, et al. Diagnosis of autoimmune pancreatitis by core needle biopsy: application of six microscopic criteria. Virchows Arch 2009:454:531-9.

23. Kloppel G, Sipos B, Zamboni G, et al. Autoimmune pancreatitis: histo- and immunopathological features. J Gastroenterol 2007;42(Suppl 18):28-31.
24. Kojima M, Sipos B, Klapper W, et al. Autoimmune pancreatitis: frequency, IgG4 expression, and clonality of T and B cells. Am J Surg Pathol 2007;31:521-8.

25. Dhall D, Suriawinata AA, Tang LH, et al. Use of immunohistochemistry for IgG4 in the distinction of autoimmune pancreatitis from peritumoral pancreatitis. Hum Pathol 2010;41:643-52

26. Chen TS, Montgomery EA. Are tumefactive lesions classified as sclerosing mesenteritis a subset of IgG4-related sclerosing disorders? J Clin Pathol 2008:61:1093-7.

27. Kamisawa T, Funata N, Hayashi Y, et al. A new clinicopathological entity of IgG4related autoimmune disease. J Gastroenterol 2003;38:982-4.

28. Zen Y, Nakanuma Y. IgG4-related disease: a cross-sectional study of 114 cases. Am J Surg Pathol 2010:34:1812-19.

29. Lin G, Li J. Elevation of serum IgG subclass concentration in patients with rheumatoid arthritis. Rheumatol Int 2010;30:837-40.

30. Engelmann R, Brandt J, Eggert $\mathrm{M}$, et al. $\lg \mathrm{G} 1$ and $\lg \mathrm{G} 4$ are the predominant subclasses among auto-antibodies against two citrullinated antigens in RA. Rheumatology (Oxford) 2008:47:1489-92.

31. Ogawa T, Tarkowski A, McGhee ML, et al. Analysis of human IgG and IgA subclass antibody-secreting cells from localized chronic inflammatory tissue. J Immunol 1989:142:1150-8.

32. Volker HU, Scheich M, Zettl A, et al. Laryngeal inflammatory myofibroblastic tumors: Different clinical appearance and histomorphologic presentation of one entity. Head Neck 2010;32:1573-8.

33. Ravi K, Chari ST, Vege SS, et al. Inflammatory bowel disease in the setting of autoimmune pancreatitis. Inflamm Bowel Dis 2009;15:1326-30.

34. Merrett J, Barnetson RS, Burr ML, et al. Total and specific lgG4 antibody levels in atopic eczema. Clin Exp Immunol 1984;56:645-52.

35. Sitaru C, Mihai S, Zillikens D. The relevance of the lgG subclass of autoantibodies for blister induction in autoimmune bullous skin diseases. Arch Dermatol Res 2007:299:1-8 


\section{$J C P$}

Numerous IgG4-positive plasma cells are ubiquitous in diverse localised non-specific chronic inflammatory conditions and need to be distinguished from IgG4-related systemic disorders

Johanna D Strehl, Arndt Hartmann and Abbas Agaimy

J Clin Pathol 2011 64: 237-243 originally published online January 12, 2011

doi: 10.1136/jcp.2010.085613

Updated information and services can be found at:

http://jcp.bmj.com/content/64/3/237

These include:

References This article cites 35 articles, 4 of which you can access for free at: http://jcp.bmj.com/content/64/3/237\#BIBL

Email alerting Receive free email alerts when new articles cite this article. Sign up in the service box at the top right corner of the online article.

Topic Articles on similar topics can be found in the following collections

Collections

Immunology (including allergy) (1652)

Degenerative joint disease (34)

Musculoskeletal syndromes (94)

Inflammation (172)

Dermatology (221)

Vascularitis (35)

\section{Notes}

To request permissions go to:

http://group.bmj.com/group/rights-licensing/permissions

To order reprints go to:

http://journals.bmj.com/cgi/reprintform

To subscribe to BMJ go to:

http://group.bmj.com/subscribe/ 